\title{
Title: Does stress increase risk of breast cancer? A 15-year prospective study.
}

\section{Running title: Stress and risk of breast cancer: A 15-year prospective study}

\section{Authors}

Phyllis Butow, $\mathrm{PhD}^{1}$ and Melanie Price, $\mathrm{PhD}^{1}$, Joseph Coll, $\mathrm{PhD}^{2}$, Katherine Tucker, $\mathrm{MBBS}^{3}$, Bettina Meiser, $\mathrm{PhD}^{4}$, Roger Milne, $\mathrm{PhD}^{5,6}$, Judith Wilson, $\mathrm{PhD}^{1}$, Louise Heiniger, $\mathrm{PhD}^{1}$, Brandi Baylock, Master of Biostatistics ${ }^{1}$, Tracey Bullen, DCP/MSc ${ }^{1}$, Prue Weideman, GradDipHealthPromEd ${ }^{7}$, Kelly-Anne Phillips, MD $^{6,7,8,9}$ on behalf of the $\mathrm{kConFab}$ investigators ${ }^{10}, \mathrm{kConFab}$ Clinical Follow-Up investigators ${ }^{11}$ and $\mathrm{kConFab}$ psychosocial investigators.

1. Centre for Medical Psychology and Evidence-based Decision-Making (CeMPED), Lifehouse Level 6North (C39Z), University of Sydney NSW 2006 Australia.

2. Psycho-Oncology Co-operative Research Group (PoCoG), Lifehouse Level 6-North (C39Z), University of Sydney NSW 2006 Australia.

3. Hereditary Cancer Clinic, Prince of Wales Hospital, High St Randwick NSW 2031 Australia

4. Psychosocial Research Group, Prince of Wales Clinical School, Level 4, Lowy Cancer Research Centre C25, The University of NSW, NSW, 2052 Australia

5. Cancer Epidemiology Centre, Cancer Council Victoria, 615 St Kilda Rd, Melbourne Victoria, 3004, Australia

6. Centre for Epidemiology and Biostatistics, Melbourne School of Population and Global Health, The University of Melbourne, Melbourne Victoria, 3010, Australia

7. Division of Cancer Medicine, Peter MacCallum Cancer Centre, Level 7, 305 Grattan St, Melbourne Victoria 3000, Australia.

8. Sir Peter MacCallum Department of Oncology, The University of Melbourne, Melbourne, Australia

9. Department of Medicine, St Vincent's Hospital, The University of Melbourne, Melbourne, Australia

10. Kathleen Cuningham Foundation Consortium for research into Familial Breast cancer (kConFab), Peter McCallum Cancer Centre, Research Division, Level 11, 305 Grattan St, Melbourne Victoria 3000, Australia

11. kConFab Clinical Follow-up Study, Peter MacCallum Cancer Centre, Level 8, 305 Grattan St, Melbourne VIC 3000, Australia

This is the author manuscript accepted for publication and has undergone full peer review but has not been through the copyediting, typesetting, pagination and proofreading process, which may lead to differences between this version and the Version of Record. Please cite this article as doi: $10.1002 /$ pon.4740 
Corresponding author: Prof Phyllis Butow, Centre for Medical Psychology and Evidence-based Decision-Making (CeMPED), Lifehouse Level 6-North (C39Z), University of Sydney NSW 2006 Australia. Ph: +61 2 93512859, Fax: +61 290365292, Email:

phyllis.butow@sydney.edu.au

\begin{abstract}
Objective: The possible impact of stress on cancer incidence remains controversial. We prospectively evaluated associations between life event stressors, social support, personality characteristics (optimism, anger control, anti-emotionality) and risk of developing primary breast cancer $(\mathrm{BCa})$, in women at increased familial risk of $\mathrm{BCa}$.

Methods: A prospective cohort, repeated measures design was employed. Recruitment was through the Kathleen Cuningham Foundation Consortium for Research into Familial breast cancer (kConFab), which collects genetic, epidemiological and clinical data from Australasian families with multiple BCa cases. Acute and chronic stressors for the prior three years, and psychosocial, clinical and epidemiological variables were measured at cohort entry and at threeyearly intervals. Cox proportional hazards regression analysis controlling for BCa risk factors and familial clustering, was undertaken. The primary outcome was histopathologically confirmed $\mathrm{BCa}$ (invasive or ductal carcinoma in situ (DCIS), including occult cases diagnosed during riskreducing mastectomy).
\end{abstract}

Results: Of 3,595 consecutive women invited to participate, 3,054 (85.0\%) consented. Of these, 2,739 (89.7\%) from 990 families (range 1-16 per family) completed at least one assessment 
point. During the study 103 women were diagnosed with BCa. No stressor or psychosocial variable or interaction between them, was significantly associated with BCa in unadjusted or adjusted models (total acute stressors $\mathrm{HR}=1.03(0.99-1 \cdot 08), \mathrm{p}=0 \cdot 19$; total chronic stressors $\mathrm{HR}=1 \cdot 0[0 \cdot 90-1 \cdot 11], \mathrm{p}=0 \cdot 98)$.

Conclusions: This study did not demonstrate an association between acute and chronic stressors, social support, optimism, anti-emotionality or anger control, and BCa risk. Women should focus on proven methods of $\mathrm{BCa}$ risk reduction.

Key words: breast cancer, high-risk, life events, prospective study, stress, 


\section{INTRODUCTION}

Breast cancer $(\mathrm{BCa})$ is the most common cancer and second most common cause of cancer death in women. ${ }^{1}$ Risk reduction, therefore, is a critical goal of health care, particularly for women at increased familial risk. Currently, risk reduction options for high-risk women, such as preventative surgery and risk-reducing medication, have potential morbidity, and uptake is variable. $^{2}$ Less intensive strategies, such as regular exercise and avoiding prolonged use of hormone replacement therapy, offer some risk-reduction, but additional strategies are urgently required. $^{2}$

A persistent belief in the general community is that life event stressors have an adverse effect on cancer risk, particularly $\mathrm{BCa}^{3}$ The literature on this topic is fraught with methodological limitations, including inadequate power and control of potential confounders, measurement error and an atheoretical approach that fails to consider potential moderators of stressor impact, such as stressor severity and chronicity, social support, personality and coping style. ${ }^{4}$ Moreover, the evidence is equivocal. The Chida et al (2008) meta-analysis ${ }^{5}$ concluded that life events do not, but a stress-prone personality, unfavorable coping styles and negative emotional responses do adversely effect cancer incidence, while noting evidence of publication bias. The Lin et al (2013) meta-analysis ${ }^{6}$ also concluded that life events as a whole are not associated with BCa risk, but high-intensity life events do increase risk of BCa. The Nielsen et al (2006) review ${ }^{4}$ suggested a fair test of the hypothesis has yet to be undertaken. 
An important methodological challenge in this research is that exposure to high-intensity stressors, such as bereavement or divorce, is sporadic and cannot be imputed over time. Also, sufficient new BCa diagnoses within the study time frame are required. Retrospective registrybased studies linking recorded stressful life events (such as divorces and deaths) with cancer incidence, offer one solution to the large samples required, and have the advantage that exposure information is independent of subjects' recall which may be biased. However, such studies are limited by the restricted range of stressful life events recorded. Case control studies (usually conducted on women with breast symptoms awaiting definitive diagnosis) are able to collect more detailed exposure data, but in a stressful pre-diagnostic environment, factors such as symptoms, family history, age and diagnostic communication might cue women regarding their breast cancer risk and bias stressful life event reporting. ${ }^{7}$ A longitudinal repeated measures design with initially unaffected participants is ideal since more detailed exposure data can be gathered, and recall will not be biased by existing symptoms or environmental factors. A large sample of women with a moderate to strong familial risk of $\mathrm{BCa}$ and/or $B R C A 1$ and $B R C A 2$ mutations, followed over time, can meet these requirements.

The aim of this study was to prospectively evaluate associations between acute and chronic life event stressors, social support, personality characteristics (optimism, anger control, antiemotionality) and the risk of developing primary $\mathrm{BCa}$ in women at increased familial risk of 
$\mathrm{BCa}$, independent of known risk factors and familial clustering.

The primary hypothesis was that exposure to high levels of acute and chronic stressors would be associated with an increased risk of developing BCa. Secondary hypotheses included that: there would be a dose-response relationship (or threshold effect), such that more severe and prolonged stressors would be associated with a greater increased risk of $\mathrm{BCa}$; and that psychosocial factors (social support, optimism, anti-emotionality, anger repression) would be associated with, or moderate the impact of stressors on, risk of BCa.

\section{METHODS}

\section{Study design}

A prospective cohort, repeated measures design was employed, and complied with the Strobe statement for cohort studies. ${ }^{8}$ Acute and chronic stressors for the prior three years, and psychosocial, clinical and epidemiological variables were measured at entry into the psychosocial study cohort and at three-yearly intervals.

\section{Recruitment Source}

Recruitment was undertaken through the Kathleen Cuningham Foundation Consortium for Research into Familial breast cancer (kConFab) ${ }^{9,10}$ established in 1995 to co-ordinate the 
collection of genetic, epidemiological and clinical data in Australasian families at high-risk of BCa.

kConFab eligibility criteria for families include having an identified deleterious mutation in $B R C A 1, B R C A 2$ or another breast cancer predisposition gene, or $\geq$ one 'high-risk' family member, ${ }^{11}$ in addition to $\geq$ four cases of breast/ovarian cancer on one side of the family, $\geq$ two living family members with breast/ovarian cancer and $\geq$ four living first or second-degree unaffected female relatives aged 18 years and over.

Detailed family history and epidemiological data are collected at entry to kConFab and blood samples taken to enable mutation testing. The kConFab Clinical Follow-Up study ${ }^{12}$ updates new cancer events epidemiological and lifestyle risk data, screening behaviors and risk-reducing surgery and medication use at three-yearly intervals using a mailed questionnaire to participants, with subsequent confirmation of reported surgery and new cancer events from medical records.

\section{Eligibility Criteria for Psychosocial Study}

kConFab women aged 18-75 years, with no personal history of cancer (except non-melanoma skin cancer or in-situ carcinoma of the cervix), were invited to participate in the psychosocial study. Non-English-literacy, and physical or mental illness affecting memory recall, were exclusion criteria. 


\section{Procedure}

The psychosocial study was introduced to women when they entered kConFab or the clinical follow-up study. Interested participants were mailed an information statement, consent form and questionnaire with a reply-paid envelope by the psychosocial study team; non-responders were

contacted by mail or phone as needed. Semi-structured phone interviews elicited acute (AS) and chronic (CS) stressful life events over the three years previous to the interview date. ${ }^{13,14}$ Interviews and questionnaires were repeated three yearly, contiguous with the clinical follow-up study. This study was approved by the institutional ethics review boards of all participating sites (ethics number H02/050/02).

\section{Measures}

\section{Primary outcome}

The primary outcome was histopathologically confirmed $\mathrm{BCa}$ (invasive or ductal carcinoma in situ, including occult cases diagnosed during risk-reducing mastectomy).

\section{Key Independent Variables}

Acute and Chronic Stressors: The Life Events and Difficulties Schedule (LEDS), ${ }^{11}$ (a semistructured interview protocol, was employed. Trained interviewers developed written clinical vignettes for each stressor elicited, including context and relevant personal and biographical 
information. An independent rater rated stressors using precise, pre-defined criteria (IRR Kappa $=0 \cdot 71-0 \cdot 78$ ), to provide a constant, objective reference point to ensure consistency of ratings of threat/loss (i.e. the severity of the stressors) across participants. Each stressor was coded on multiple features, including:

- $\quad$ Type - Acute $(A S)$ (discrete event) or chronic (CS) (continuing for at least 6 months);

- $\quad$ Time - Date (closest month); if CS duration (years) and current (yes/no);

- $\quad$ Severity (S) (mild, moderate, high, severe); and

- Independence from personal or familial risk of $\mathrm{BCa}$ or $\mathrm{BCa}$ diagnosis; $\underline{\mathrm{BCa} \text { risk-related }}$

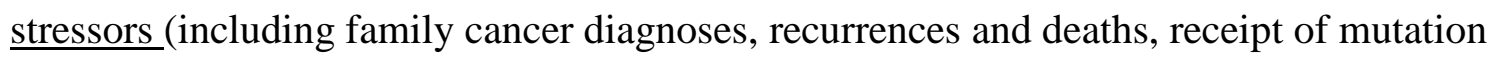
testing results (for self or a family member) and risk-reducing surgery) were excluded from $\underline{\text { all analyses). }}$

Examples are: death of a spouse/child (AS: severe); buying/selling a home (AS: moderate); handicapped child requiring fulltime care (CS: severe); ongoing acrimonious dispute with neighbours over noise (CS: moderate).

\section{Psychosocial Variables}

Psychosocial variables included those previously identified as predictors or moderators of the impact of stressors on BCa risk (social support and personality factors), using psychometrically proven measures. 
Social Support: The eight-item Duke-UNC Functional Social Support Questionnaire measures satisfaction with social support. ${ }^{15}$ Total scores range from eight to 40 ; higher scores indicate greater social support.

Optimism: The 12-item Life Orientation Test (LOT) scale ${ }^{16}$ measures dispositional optimism. Total scores range from 0 to 32; high scores indicate greater optimism.

Anti-Emotionality: The four-item Anti-Emotionality Scale ${ }^{17}$ assesses absence of emotional behaviour. Scores range from one to four; higher scores indicate more anti-emotional behaviour.

Anger Control: The seven-item subscale of the Courtauld Emotional Control Scale ${ }^{18}$ measures anger control. Total scores range from seven to 28; higher scores indicate greater control.

\section{Potential Covariables/Confounders}

Current Anxiety and Depression: We controlled for current anxiety and depression, which may influence self-report of stressors and psychosocial variables, in all models containing psychosocial variables. The seven-item subscales of the Hospital Anxiety and Depression Scale ${ }^{19}$ measure anxiety and depression over the past week. Scores range between zero and 21; high scores indicate greater current anxiety and depression. 
As known at last time-point: mutation status (BRCA1 mutation, BRCA2 mutation, no BRCA1 or BRCA2 mutation, untested/unknown); number of $1^{\text {st }}$ and $2^{\text {nd }}$ degree relatives with a) BCa and b) ovarian cancer; age at menarche; number of live births; parity by breast feeding (nulliparous, parous and breast fed, parous and not breast fed); smoking history (current, former, never); exercise (sufficiently active, insufficiently active, sedentary, unknown). ${ }^{20}$

Time-varying: bilateral salpingo-oophorectomy; benign breast disease; hormone replacement therapy use (never, not within last three years, within last three years, unknown); oral contraception use (never, not within three years, within last three years, unknown); body mass index; and anxiety and depression (where applicable).

\section{STATISTICAL METHODS}

Cox proportional hazards regression analysis, with the time scale anchored to the age at the start and end of the time period covered by each LEDS interview, was performed to examine the association between stressors recorded in each three-year period and diagnosis of BCa in the next three-year period. Mutation status was entered as a stratification variable to allow for differing baseline hazard functions. The analysis was adjusted for potential confounders and included a random family effect to accommodate covariance due to familial clustering. Women undergoing risk-reducing mastectomy were censored at that date. Number and severity of stressors, and each 
psychosocial variable, were evaluated in separate models. Statistical tests were two-sided with a Type 1 error rate of $5 \%$ for main effects.

Simulation studies indicate that ten events per parameter estimated provides reliable estimates of the hazard ratios. ${ }^{21}$ Over the study period, 103 women were diagnosed with $\mathrm{BCa}$; therefore, a model with four stressor variables and four psychosocial variables (our final model) can be evaluated reliably. With insufficient power to evaluate all the covariables, they are not individually interpreted. Analysis was conducted by a qualified biostatistician (JC).

\section{RESULTS}

Of 3,595 eligible women consecutively invited to participate in the psychosocial study between May 2001 and December 2010, 3,054 (85.0\%) consented. Of these 2,739 (89.7\%) from 990 families (range 1-16 per family) completed at least one LEDS interview and were included in the analyses. The mean follow-up was 7.2 years, with 645 (23.5\%) completing one data time-point, $916(33.4 \%)$ completing two, $980(35.8 \%)$ completing three and $200(7 \cdot 3 \%)$ completing four (attenuated with study closure in December 2011). During the study period 103 women from 97 families were diagnosed with BCa.

On average, women were aged 45.0 years at study entry, $6 \%$ were $B R C A 1$ and $6 \%$ were $B R C A 2$ mutation positive, $34 \%$ were confirmed $B R C A 1$ or $B R C A 2$ mutation negative and $54 \%$ were 
without a known $B R C A 1$ or $B R C A 2$ mutation within their family and therefore not tested. On average the women reported scores at the upper end of the range in social support and optimism, and in the lower end of the range in anti-emotionality and anger control (see Supplementary Table 1).

Descriptive data for acute and chronic stressors, frequency and severity, are shown in Table 1. Most stressors, both acute and chronic, were mild or moderate in severity. The distribution of stressors was similar across those with and without BCa.

Unadjusted and adjusted hazard ratios and p-values for stressor variables and psychosocial variables are shown in Table 2. The total number of AS and CS were not associated with BCa risk (Model 1). Model 2 included the total number of AS and CS by severity (mild, moderate, high, severe). The risk of BCa was similar across severity for AS. For CS, the hazard ratio was somewhat greater for high and severe CS than for mild and moderate CS, although the confidence intervals are wide. A similar pattern is observable in Model 3, where the number of AS and CS were collapsed into two categories: low-moderate and high-severe. Although none of the stressor variables reached statistical significance, the hazard ratio (HR) for the high-severe CS was 1.28 (95\% Confidence Interval (CI) 0.88-1.85) in the adjusted model (HR=1.31; CI 0.921.87 unadjusted model). As the study was powered to explore a threshold of at least one highsevere stressor, Model 4 examined the threshold effect of exposure to high-severe acute stressors 
and chronic stressors in the absence of mild-moderate stressors, although similarly to Model 3, neither reached statistical significance.

Models 5-8 evaluated the association between each time-varying psychosocial variable (adjusted for anxiety and depression) and BCa diagnosis. None of the psychosocial variables reached statistical significance.

Model 9, the full model, included the total number of low-moderate AS, high-severe AS, lowmoderate CS, and high-severe CS, and the time-varying psychosocial variables. None of the stressors or psychosocial variables were significantly associated with BCa in the unadjusted or adjusted models. Interactions between the stressor variables and the psychosocial variables were tested and none reached statistical significance after adjusting for covariables. The results of Model 9 are shown in Table 2 and Supplementary Figures 1 and 2.

\section{DISCUSSION}

In this rigorous, prospective study evaluating the impact of stressors and psychosocial variables on $\mathrm{BCa}$ risk, we found no significant associations, although there was a trend for significance for high severe chronic life stress (HR: 0-91-2.04, $\mathrm{p}=0.13$ ). The study addressed methodological issues which have limited interpretation of prior studies, including: objective, consistent ratings 
of stressors, differentiating acute and chronic stressors of different types (e.g. illness, financial); assessing stressors prior to diagnosis to avoid recall bias; and controlling for BCa risk factors, ${ }^{4}$ anxiety and depression at time of self-reported psychosocial data collection, and potential behavioural consequences of stressors such as smoking. Stressors related to BCa risk were excluded from all analyses.

The results may not generalise to women in the general population, not at increased familial risk. However, internationally, most rigorous studies have also failed to find an association between psychosocial factors and cancer, such as a large prospective study of life events in 11,000 women from the general population with 313 incident BCas, (Surtees et al, 2010), ${ }^{22}$ the UK Million Women study ${ }^{23}$, a recent registry-based Danish study exploring prolonged job strain and risk of cancer in 6,571 women, ${ }^{24}$ a prospective study of 10,519 Finnish women measuring selfperceived stress levels in Finland, ${ }^{25}$ and a prospective cohort study of 30,277 Japanese residents. $^{26}$

In contrast, the Finnish Twin Cohort, ${ }^{27}$ involving 10,808 women (180 incident BCas) found that severe events, (including divorce/separation, death of a husband/close relative/friend), were associated with increased risk of $\mathrm{BCa} .{ }^{27}$ Thus, the literature on the general population remains somewhat conflicted. None of these studies used the gold-standard approach to measuring 
stressors used here. It is also possible that moderating variables not measured, such as coping strategies tailored to different stressors, may influence impact of stressors on BCa risk.

\section{Clinical Implications}

Over the past 40 years, women have been exposed to strong messages about the importance of 'thinking positively' and reducing stress in their lives, which can add to the burden of guilt in those who develop cancer, who feel they have somehow failed. Our results, based on rigorous methodology, add to the growing literature providing reassurance to women at increased risk of $\mathrm{BCa}$, who are concerned that the (often unavoidable) stressors in their lives may increase their risk of $\mathrm{BCa}$. Of course, reducing the impact of stress on general health and quality of life remains a worthwhile goal for women.

\section{Limitations of the Study}

The study was powered assuming a $5.7 \%$ rate of $\mathrm{BCa}$ and an $18 \%$ exposure rate of at least one high-severe AS or CS over an average follow-up of ten years in a cohort of 3100 women. This roughly equates to having $80 \%$ power to detect a HR as small as 1.73 . We actually observed a $\mathrm{BCa}$ rate of $3.8 \%$ in our cohort of 2,739 women with an average follow-up of 7.2 years. Of the 6217 interviews included in analysis, $2675(43.0 \%)$ had at least one high-severe AS or CS (39.0\% with at least one AS plus $13.6 \%$ with at least one CS less $9.6 \%$ with at least one AS and CS). Therefore, we had $80 \%$ power to detect a HR as small as: 1.76 for at least one AS, and $2 \cdot 24$ 
for at least one CS (Model 4). Thus, the power to detect HRs of the magnitude of those observed in Model 9 was modest. The very right-skewed HR for high severe chronic events may have been significant if power was higher.

Our response rate of $85 \%$ was high, but women with more or less stress in their lives may have been differentially attracted to the study. We controlled for a very comprehensive list of potential confounders but some aspects (such as coping style) were not assessed. It is possible that our choice of women from multiple-case BCa families was flawed and that the impact of stressors may be inconsequential in comparison to the impact of genetic influences.

\section{Conclusions}

Given the lack of evidence found for an association between stressors and psychosocial factors and $\mathrm{BCa}$, we suggest that women at increased risk of $\mathrm{BCa}$ focus on proven methods of risk reduction such as close monitoring, risk-reducing medication or, for those at high risk, surgery.

\section{Acknowledgements}

We wish to thank: 1) the kConFab contributors, including Heather Thorne, Eveline Niedermayr, kConFab research nurses and the Family Cancer Clinics in Australia; 2) the kConFab Clinical Follow up study; 3 ) the kConFab psychosocial study group members, including Sue-Anne 
McLachlan, Barbara Bennett, Christopher Tennant, Margaret Charles and Ms Gerda Evans; and 4) the women who participated in the study.

\section{Acknowledgement of funding}

The kConFab psychosocial study received funding from the National Health and Medical

Research Council (NHMRC) of Australia Project Grants 2001-2011; \#153824, 301930, 457316.

kConFab received funding from the National Breast Cancer Foundation; NHMRC; the

Queensland Cancer Fund; the Cancer Councils of New South Wales, Victoria, Tasmania and South Australia; and the Cancer Foundation of Western Australia.

\section{References}

1. Australian Institute of Health and Welfare. Breast cancer in Australia: an overview. Cancer Series no. 71. Cat. no. CAN 67. 2012; AIHW: Canberra.

2. Hartmann LC, Lindor NM. The role of risk-reducing surgery in hereditary breast and ovarian cancer. New England Journal of Medicine 2016; 374: 454-468.

3. Dumalaon-Canaria, JA, Hutchinson AD, Prichard I, Wilson C. What causes breast cancer? A systematic review of causal attributions among breast cancer survivors and 
how these compare to expert-endorsed risk factors. Cancer Causes \& Control 2014; 25(7): 771-785.

4. Nielsen NR, Grønbaek M. Stress and breast cancer: a systematic update on the current knowledge. Nat Clin Pract Oncol 2006; 3(11): 612-20.

5. Chida Y, Hamer M, Wardle J, Steptoe A. Do stress-related psychosocial factors contribute to cancer incidence and survival? Nature Clinical Practice Oncology 2008; 5(8): 466-475.

6. Lin Y, Wang C, Zhong Y, Huang X, Peng L, Shan G, Wang K, Sun Q. Striking life events associated with primary knowledge. Nature Clinical Practice Oncology 2006; 3(11): 612-620.

7. Johansen C, $\underline{\text { Schüz J }}$ Andreasen A-M, and Dalton SO. Study designs may influence results: the problems with questionnaire-based case-control studies on the epidemiology of glioma Br J Cancer. 2017 Mar 28; 116(7): 841-848.

8. https://www.strobe-statement.org/index.php?id=available-checklists

9. Mann GJ, Thorne H, Balleine RL, Butow PN, Clarke CL, Edkins E, Evans GM, Fereday S, Haan E, Gattas M, Giles GG, Goldblatt J, Hopper JL, Kirk J, Leary JA, Lindeman G, Niedermayr E, Phillips KA, Picken S, Pupo GM, Saunders C, Scott CL, Spurdle AB, Suthers G, Tucker K, Chenevix-Trench G, Kathleen Cuningham Consortium for Research in Familial Breast Cancer. Analysis of cancer risk and BRCA1 and BRCA2

This article is protected by copyright. All rights reserved. 
mutation prevalence in the $\mathrm{kConFab}$ familial breast cancer resource. Breast Cancer Research 2006; 8(1): R12.

10. Osborne RH, Hopper JL, Kirk JA, Chenevix-Trench G, Thorne HJ, Sambrook JF. kConFab: a research resource of Australasian breast cancer families. Medical Journal of Australia 2000; 172(9),: 463-464.

11. iSource National Breast Cancer Centre. Advice about familial aspects of breast cancer and ovarian cancer: a guide for health professionals. NBCC, Woolloomooloo, NSW. www.nbcc.org.au. Accessed November 2017.

12. Phillips KA, Butow PN, Stewart AE Chang JH, Weideman PC, Price MA, McLachlan SA, Lindeman GJ, McKay MJ, Friedlander ML, Hopper JL, kConFab Investigators. Predictors of participation in clinical and psychosocial follow-up of the kConFab breast cancer family cohort. Familial Cancer 2005; 4(2): 105-113.

13. Brown GW, Harris T. Social origins of depression: A study of psychiatric disorder in women. 1979; London: Tavistock.

14. Price MA, Butow PN, Lo SK, Wilson J, Kathleen Cunningham Consortium for Research into Familial Breast Cancer (kConFab) Psychosocial Group. Predictors of cancer worry in unaffected women from high risk breast cancer families: risk perception is not the primary issue. Journal of Genetic Counseling 2007; 16(5): 635-44.

This article is protected by copyright. All rights reserved. 
15. Broadhead WE, Gehlbach SH, de Gruy FV, Kaplan BH. The DUKE-UNC Functional Social Support Questionnaire - Measurement of social support in fsamily medicine patients. Medical Care 1988; 26(7): 709-723.

16. Scheier MF, Carver CS. Optimism, coping and health - Assessment and implications of gernalized outcome expectancies. Health Psychology 1985; 4(3): 219-247.

17. Bleiker EM, Van der Ploeg HM, Hendriks JH, Ader HJ. Personality factors and breast cancer development: A prospective longitudinal study. Journal of the National Cancer Institute 1996; 88(20): 1478-1482.

18. Watson M, Greer S. Development of a questionnaire measure of emotional control. Journal of Psychosomatic Research 1983; 27(4): 299-305.

19. Zigmond AS, Snaith RP. The Hospital Anxiety and Depression Scale. Acta Psychiatrica Scandinavica 1983; 67(6): 361-370.

20. Department of Health (Australia): Australia's Physical Activity and Sedentary Behaviour Guidelines. (http://www.health.gov.au/internet/main/publishing.nsf/content/healthpubhlth-strateg-phys-act-guidelines\#apaadult). Accessed March 2017.

21. Peduzzi P1, Concato J, Feinstein AR, Holford TR. Importance of events per independent variable in proportional hazards regression analysis. II. Accuracy and precision of regression estimates. Journal of Clinical Epidemiology 1995; 48(12): 1503-1510.

22. Surtees PG, Wainwright NW, Luben RN, Khaw KT, Bingham SA. No evidence that social stress is associated with breast cancer incidence. Breast Cancer Research and 
Treatment 2010; 120: 169-174.

23. Liu B, Floud S, Pirie K, Green J, Peto R, Beral V for the Million Women Study Collaborators. Does happiness itself directly affect mortality? The prospective UK Million Women Study Lancet 2016; 387: 874-81.

24. Vesterlund GK, Hoeg BL, Johansen C, Heitmann BL, Bidstrup P. Prolonged job strain and subsequent risk of cancer in women - a longitudinal study, based on the Danish nurse cohort. Acta Oncologica 2017; 56(2): 301-306.

25. Lillberg K, Verkasalo PK, Kaprio J, Teppo L, Helenius H, Koskenvuo M. Stress of daily activities and risk of breast cancer: A prospective cohort study in Finland. International Journal of Cancer 2001; 91(6): 888-93.

26. Nakya N, Tsubono Y, Hosokawa T, Nishino Y, Ohkubo T, Hozawa A, Shibuya D, Fugudo S, Fukao A, Tsuji I, Hisamichi S. Personality and the risk of cancer. Journal of the Nat Cancer Institute 2003; 95(11), 799-805.

27. Lillberg K, Verkasalo PK, Kaprio J, Teppo L, Helenius H, Koskenvuo M. Stressful Life Events and Risk of Breast Cancer in 10,808 Women: A Cohort Study. American Journal of Epidemiology 2003; 157(5): 415-423.

This article is protected by copyright. All rights reserved. 
Table 1. Distribution of the average number of acute and chronic stressors per woman (averaged over each woman's follow-up time)

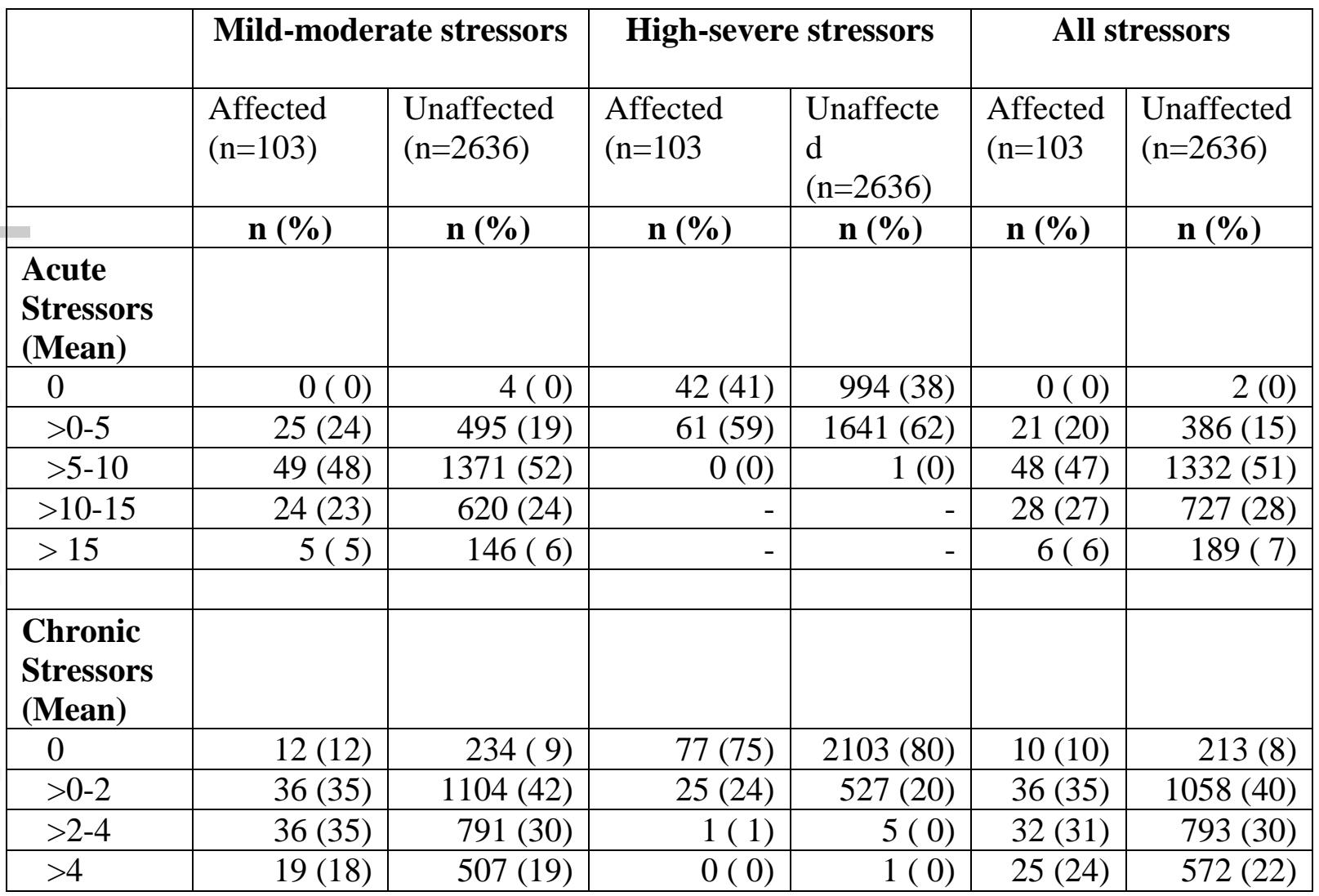

This article is protected by copyright. All rights reserved. 
Table 2. Unadjusted and Adjusted Hazard Ratios (HR) and 95\% Confidence Intervals (CI) of a breast cancer diagnosis

\begin{tabular}{|l|l|l|l|l|l|l|}
\hline \multicolumn{1}{|c|}{ Variable } & \multicolumn{3}{|c|}{ Unadjusted } & \multicolumn{3}{c|}{${ }^{\#}$ Adjusted } \\
\hline MODEL 1 & HR & \multicolumn{9}{|c|}{$95 \%$ CI } & p-value & HR & $95 \%$ CI & p-value \\
\hline No. Acute Stressors (AS) & 1.03 & $0.98-1.08$ & 0.24 & 1.03 & $0.99-1.08$ & 0.19 \\
\hline No. Chronic stressors (CS) & 1.00 & $0.90-1.10$ & 0.95 & 1.00 & $0.90-1.11$ & 0.98 \\
\hline & & & & & & \\
\hline MODEL 2 & & & & & & \\
\hline No. AS - mild & 1.03 & $0.98-1.09$ & 0.27 & 1.04 & $0.98-1.10$ & 0.16 \\
\hline No. AS - moderate & 1.03 & $0.92-1.15$ & 0.63 & 1.02 & $0.91-1.15$ & 0.69 \\
\hline No. AS - high & 1.03 & $0.81-1.29$ & 0.84 & 1.00 & $0.78-1.28$ & $>0.99$ \\
\hline No. AS - severe & 0.87 & $0.52-1.44$ & 0.58 & 0.95 & $0.57-1.56$ & 0.83 \\
\hline No. CS - mild & 0.99 & $0.88-1.11$ & 0.82 & 0.99 & $0.88-1.12$ & 0.86 \\
\hline No. CS - moderate & 0.93 & $0.73-1.18$ & 0.53 & 0.93 & $0.73-1.19$ & 0.57 \\
\hline No. CS - high & 1.21 & $0.75-1.94$ & 0.44 & 1.18 & $0.73-1.90$ & 0.51 \\
\hline No. CS - severe & 1.58 & $0.72-3.48$ & 0.25 & 1.24 & $0.52-2.98$ & 0.63 \\
\hline & & & & & & \\
\hline MODEL 3 & & & & & & \\
\hline No. AS - mild-moderate & 1.03 & $0.98-1.08$ & 0.21 & 1.04 & $0.99-1.09$ & 0.14 \\
\hline No. AS - high-severe & 0.97 & $0.79-1.20$ & 0.78 & 0.96 & $0.77-1.19$ & 0.69 \\
\hline No. CS - mild-moderate & 0.98 & $0.88-1.08$ & 0.63 & 0.98 & $0.88-1.09$ & 0.65 \\
\hline No. CS - high-severe & 1.31 & $0.92-1.87$ & 0.13 & 1.28 & $0.88-1.85$ & 0.19 \\
\hline & & & & & & \\
\hline MODEL 4 & & & & & & \\
\hline $\begin{array}{l}\text { One or more AS - high- } \\
\text { severe }\end{array}$ & 1.33 & $0.88-2.00$ & 0.18 & 1.25 & $0.82-1.91$ & 0.30 \\
\hline $\begin{array}{l}\text { One or more CS - high- } \\
\text { severe }\end{array}$ & 1.49 & $0.91-2.46$ & 0.12 & 1.57 & $0.94-2.62$ & 0.09 \\
\hline & & & & & & \\
\hline MODEL 5 Social Support & 1.01 & $0.98-1.04$ & 0.31 & 1.00 & $0.97-1.03$ & 0.97 \\
\hline & & & & & & \\
\hline MODEL 6 Optimism & 1.04 & $1.00-1.08$ & 0.08 & 1.03 & $0.99-1.08$ & 0.18 \\
\hline & 0.83 & $0.57-1.20$ & 0.32 & 0.84 & $0.57-1.25$ & 0.39 \\
\hline $\begin{array}{l}\text { MODEL 7 Anti- } \\
\text { Emotionality }\end{array}$ & 1.00 & $0.94-1.07$ & 0.92 & 1.00 & $0.93-1.07$ & 0.93 \\
\hline & & & & & & \\
\hline MODEL 8 Anger & & & & & & \\
\hline
\end{tabular}

This article is protected by copyright. All rights reserved. 


\begin{tabular}{|l|l|l|l|l|l|l|}
\hline & & & & & & \\
\hline MODEL 9 & & & & & & \\
\hline No. AS - mild-moderate & 1.03 & $0.98-1.09$ & 0.21 & 1.05 & $0.99-1.10$ & 0.10 \\
\hline No. AS - high-severe & 0.97 & $0.77-1.21$ & 0.76 & 0.93 & $0.73-1.19$ & 0.57 \\
\hline No. CS - mild-moderate & 1.00 & $0.90-1.12$ & 0.94 & 1.00 & $0.89-1.13$ & 0.96 \\
\hline No. CS - high-severe & 1.29 & $0.85-1.95$ & 0.23 & 1.36 & $0.91-2.04$ & 0.13 \\
\hline Social Support & 1.01 & $0.98-1.04$ & 0.65 & 1.00 & $0.97-1.04$ & 0.97 \\
\hline Optimism & 1.04 & $0.99-1.08$ & 0.11 & 1.03 & $0.98-1.08$ & 0.23 \\
\hline Anti-Emotionality & 0.75 & $0.50-1.11$ & 0.15 & 0.75 & $0.49-1.14$ & 0.17 \\
\hline Anger & 1.01 & $0.94-1.08$ & 0.80 & 1.00 & $0.93-1.07$ & 0.99 \\
\hline
\end{tabular}

$\mathrm{AS}=$ Acute stressors; $\mathrm{CS}=$ Chronic stressors

Mutation status (BRCA1, BRCA2, negative BRCA1/2, untested/unknown) was specified as a stratification variable in all unadjusted and adjusted analyses.

\# Adjusted for (as known at last data collection): No. of $1^{\text {st }} \& 2^{\text {nd }}$ degree relatives with a) BCa and b) ovarian cancer; age at menarche, no. live births, parity by breast feeding (nulliparous, parous and breast fed, parous and not breast fed), smoking history (current, former, never), exercise (sufficiently active, insufficiently active, sedentary, unknown); and adjusted for (time-varying): bilateral salpingo-oophorectomy (BSO), benign breast disease, HRT use (never, not within last 3 years, within last 3 years, unknown), oral contraception use (never, not within 3 years, within last 3 years, unknown), body mass index. Models 5 through 9 additionally control for time-varying anxiety and depression. 


\section{University Library}

\section{- M M N E R VA A gateway to Melbourne's research publications}

Minerva Access is the Institutional Repository of The University of Melbourne

\section{Author/s:}

Butow, P;Price, M;Coll, J;Tucker, K;Meiser, B;Milne, R;Wilson, J;Heiniger, L;Baylock, B;Bullen, T;Weideman, P;Phillips, K-A

Title:

Does stress increase risk of breast cancer? A 15-year prospective study

\section{Date:}

2018-08-01

\section{Citation:}

Butow, P., Price, M., Coll, J., Tucker, K., Meiser, B., Milne, R., Wilson, J., Heiniger, L., Baylock, B., Bullen, T., Weideman, P. \& Phillips, K. -A. (2018). Does stress increase risk of breast cancer? A 15-year prospective study. PSYCHO-ONCOLOGY, 27 (8), pp.1908-1914. https://doi.org/10.1002/pon.4740.

Persistent Link:

http://hdl.handle.net/11343/283886 